Л. Г. Корнієнко ${ }^{1}$ В. Д. Карлов ${ }^{1}$, А. М. Артеменко ${ }^{2}$

${ }^{1}$ Харківській національний університет Повітряних Сил імені Івана Кожедуба, Харків, Україна

${ }^{2}$ Генеральний штаб Збройних Сил України, Київ, Україна

\title{
ЗОНИ ВИЯВЛЕННЯ РЛС МЕТРОВОГО ДІАПАЗОНУ 3 ВРАХУВАННЯМ ОСОБЛИВОСТЕЙ ПОБУДОВИ І ВИКОРИСТАННЯ АНТЕННОЇ СИСТЕМИ
}

\begin{abstract}
Предметом дослідження є методика розрахунку зон виявлення РЛС метрового діапазону, на формування якої істотно впливає Земля. Метою роботи є розробка та аналіз математичної моделі зони виявлення, яка узагальнює відому модель на випадок, коли антена РЛС не має фазового центру або він не збігається з початком обраної системи координат для розрахунку діаграми спрямованості антени. Модель базується на методі відбиттєвої трактовки і враховує особливості побудови антени. Випромінюючі елементи антени у вигляді хвильових каналів розташовані на двох поверхах, що дозволяє підбором висот поверхів і їх збудження сигналами з визначеними амплітудами і початковими фазами зменшити глибину провалів в діаграмі спрямованості в певних кутових секторах.. У таких антенах зазвичай відсутній фазовий центр, тому в математичній моделі зони виявлення враховані не тільки амплітудні, а й фазові характеристики антени. Це дозволило врахувати відмінності фаз полів у напрямках на ціль і точку відображення й уточнити результат інтерференції прямих і відбитих хвиль. Проведено розрахунки зон виявлення, що ілюструють вплив на їх параметри електричних властивостей землі, висот підйому антени і її нахилу відносно горизонту. Математична модель реалізована за допомогою доступного і простого комп'ютерного математичного пакета Mathcad. Kомп'ютерна модель дозволяє при змінах конструкції антени або електричних параметрів Землі оперативно оцінювати зони виявлення та можливості їх управління для поліпшення умов виявлення цілей під певними кутами місця.
\end{abstract}

Ключов і слов а: зона виявлення, метод відбиттєвої трактовки, пряма і відбита хвилі, електричні параметри земної поверхні, коефіцієнт відбиття, висота підйому приймально-передавальної антени, амплітудна і фазова діаграми, інтерференційний множник, максимальна дальність виявлення.

\section{Вступ}

Для ефективного виконання бойових задач по захисту від засобів повітряного нападу важливо мати інформацію за параметри зони виявлення РЛС, та способи їх зміни для адаптації до повітряної обстановки. Така інформація також важлива при розгортанні РЛС на нових позиціях. В умовах обмежених можливостей по вимірюванню діаграми спрямованості антени (наприклад методом обльоту) з врахуванням впливу на неї земної поверхні, стає актуальним пошук інших способів оцінки зон виявлення. Привабливим $\epsilon$ метод математичного моделювання, який дозволяє оперативно здійснювати пошук раціональних (оптимальних) рішень при застосуванні комп’ютерних програм. Загальні теоретичні дані для математичного моделювання зон виявлення відомі, наприклад в $[1,2,3]$. Однак, внаслідок певних особливостей побудови антен РЛС метрового діапазону $[4,5]$ вони, як показують дослідження, потребують доповнення і конкретизації, зокрема застосування в опису електромагнітних процесів, окрім амплітудних, ще й фазових характеристик антени.

Метою роботи є розробка математичної моделі зони виявлення РЛС метрового діапазону з врахуванням особливостей побудови і способів використання антени та аналіз параметрів зон виявлення i можливостей їх регулювання на позиціях з різним типом земної поверхні.

Основна увага приділяється аналізу математичних співвідношень, області їх застосування та відповідності реальним даним.

\section{Виклад основного матеріалу}

Математична модель зони виявлення. Максимальна дальність виявлення Д цілі (3 ефективною відбиттєвою поверхнею $\sigma_{\Perp}$ ) РЛС з граничною чутливістю приймача $P_{n p \text {.мін }}$, 3 потужністю випромінювання $P$ антеною із коефіцієнтом спрямованої дії (КСД) $D(\theta, \varphi)=\mathrm{D}_{\mathrm{M}} F_{A}^{2}(\theta, \phi)$ на довжині хвилі $\lambda$, визначається виразом $[1,2]$

$$
\begin{gathered}
Д=Д_{B} F(\theta, \phi), \\
Д_{B}=\sqrt[4]{\left[P D_{M}{ }^{2} \lambda^{2} \sigma_{u}\right] /\left[(4 \pi)^{3} P_{n p . \min }\right]},
\end{gathered}
$$

де Д льному просторі, $\mathrm{F}((\theta, \varphi)$ - амплітудна діаграма спрямованості (ДС) приймально-передавальної антени 3 врахуванням впливу Землі $(\theta-$ кут місця, $\varphi$ - азимут), $\mathrm{D}_{\mathrm{M}}$ - максимальне значення КСД антени, яка у вільному просторі має нормовану амплітудну ДС $F_{A}(\theta, \phi)$.

На дальність виявлення РЛС метрового діапазону суттєво впливає Земля, бо частина поля випромінювання антени, що піднята на висоту $\mathrm{h}_{\mathrm{A}}$, відбивається від поверхні Землі і підсумовується з прямою хвилею в точці спостереження, що приводить, в залежності від фазових співвідношень хвиль, до збільшення або зменшення результуючої амплітуди поля. Для гладкої поверхні Землі відбиття можна вважати дзеркальним, для розрахунку поля використовують метод відбиттєвої трактовки $[1,2]$, у відповідності з яким вираз для ДС в дальній зоні антени та iï дзеркального зображення (рис. 1) має в площині кута місця такий вигляд:

$$
\begin{gathered}
F(\theta)=F_{A}(\theta) \times \\
\times \sqrt{1+\Gamma^{2} \frac{F_{A}^{2}(-\theta)}{F_{A}^{2}(\theta)}+2 \Gamma \frac{F_{A}(-\theta)}{F_{A}(\theta)} \cos \left(2 k h_{A} \sin \theta-\beta\right)},
\end{gathered}
$$




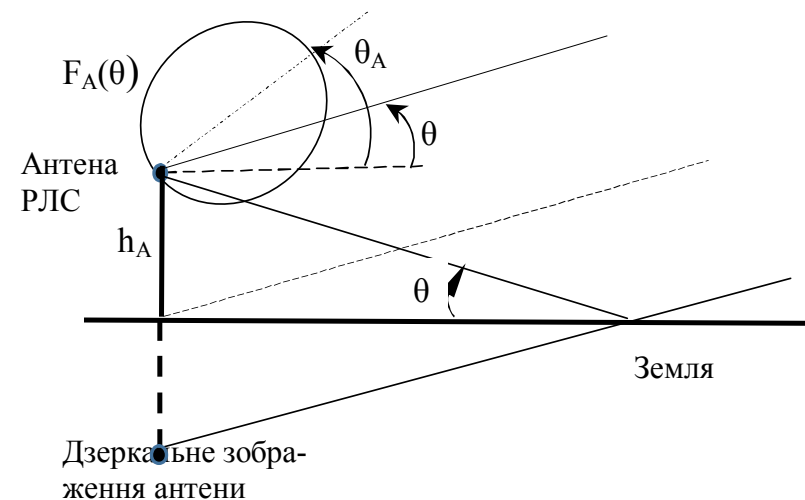

Рис. 1. До методу відбиттєвої трактовки

де $\mathrm{k}=2 \pi / \lambda$ - хвильове число вільного простору; $\mathrm{F}_{\mathrm{A}}(\theta)$, $\mathrm{F}_{\mathrm{A}}(-\theta)$ - значення нормованої амплітудної ДС антени в напрямках на ціль та на точку відбиття відповідно; $\Gamma^{\prime}=\Gamma e^{j \beta}-$ коефіцієнт відбиття від гладкої поверхні: його модуль $\Gamma$ та аргумент $\beta$, який визначає фазовий зсув між відбитою та падаючою хвилями. Коефіцієнт відбиття залежить від кута $\theta$, поляризації падаючих хвиль та відносної комплексної діелектричної проникності земної поверхні

$$
\varepsilon^{\prime}=\varepsilon-j 60 \lambda \sigma .
$$

Одна і та ж земна поверхня з відносною діелектричною проникністю $\varepsilon$ і питомою провідністю $\sigma$ в залежності від довжини хвилі $\lambda$ може діяти як провідник $(\varepsilon<<60 \lambda \sigma)$, діелектрик $(\varepsilon>>60 \lambda \sigma)$ або напівпровідник $(\varepsilon \approx 60 \lambda \sigma)$.

Другий множник в (2) 3 квадратним коренем визначає модуль інтерференційного множника, який описує результат інтерференції прямої і відбитої хвиль в напрямку кута $\theta$ при орієнтації максимуму амплітудної ДС в напрямку кута $\theta_{\mathrm{A}}$.

Антени РЛС виявлення метрового діапазону для отримання потрібної форми зони виявлення будують двоповерховими (двоярусними) з можливістю механічного повороту у вертикальній площині та 3 нерівномірним і несинфазним збудженням [4]. При такому збудженні геометричний центр антени (піднятий на висоту $\mathrm{h}_{\mathrm{A}}$ ) не є фазовим центром, ДС антени у вільному просторі, яка розраховується відносно центру, стає комплексною, і тому вираз (2) для цього випадку стає некоректним, бо він не враховує фазові співвідношення полів випромінювання антени в напрямку на ціль та на точку відбиття [6].

Врахування вказаного ефекту приводить до наступного виразу для максимальної дальності виявлення РЛС

$$
\begin{gathered}
\text { Д }=Д_{B} F_{A}(\theta) \times \\
1+\Gamma^{2} \frac{F_{A}^{2}(-\theta)}{F_{A}^{2}(\theta)}+2 \Gamma \frac{F_{A}(-\theta)}{F_{A}(\theta)} \cos \left(2 k h_{A} \sin \theta-\beta-\zeta\right)
\end{gathered}
$$

де $\zeta=\arg \frac{F_{A}^{\prime}(-\theta)}{F_{A}^{\prime}(\theta)}-$ аргумент відношення комплексної ДС антени в напрямках на точку відбиття і на ціль відповідно. Ця величина визначає різницю фаз прямої і відбитої хвиль, яка виникає внаслідок ви- промінювання антеною хвилі з несферичним фронтом відносно геометричного центру антени.

Будемо розглядати нормовану до дальності Д зону виявлення РЛС у координатах: нормована висота над плоскою землею $\mathrm{H}(\theta)=(Д \sin \theta) / Д_{\text {в }}$, нормована горизонтальна дальність $\mathrm{R}(\theta)=(Д \cos \theta) / Д_{\text {в }}$ Це дозволяє абстрагуватися від енергетичних показників РЛС та типу цілі і зосередитися на аналізі впливу параметрів антени та Землі на зону виявлення.

Аналітична модель ДС антени. ДС антени у вертикальній площині формується двохелементною вертикальною антенною решіткою 3 відстанню між елементами $\mathrm{d}=\mathrm{h}_{\mathrm{B}}-\mathrm{h}_{\mathrm{H}}$, де $\mathrm{h}_{\mathrm{B}}, \mathrm{h}_{\mathrm{H}}-$ висоти підйому верхнього та нижнього ярусів антени. Елементом $\epsilon$ директорна антена з горизонтальним розташуванням вібраторів, для розрахунку ДС якої потрібно використовувати складні чисельні методи, основу яких складає розрахунок розподілу струму в антені методами обчислювальної електродинаміки [7]. Директорна антена за принципом дії аналогічна антенам біжучих хвиль [8], що дозволяє скористатися результатами теорії цих антен для визначення апроксимаційного виразу для ДС директорної антени. Визначено, що функція

$$
\begin{gathered}
f_{e}(\theta)=\mid \frac{\sin \psi}{\psi} \cos (0,7 \theta) ; \\
\psi=\frac{2,7 \pi}{\lambda}(1,44-\cos \theta)
\end{gathered}
$$

3 точністю до 10\% описує значення основних показників реальної ДС директорної антени РЛС [5] в області головного і першого бічного пелюсток на робочій частоті. Нормована ДС директорної антени наведена на рис.2 (пунктир). Напрямок головного максимуму ДС орієнтований уздовж iіi осі.

Згідно з теорією антенних решіток [9] нормована комплексна ДС антени у вертикальній площині у місцевій системі координат $з$ початком у геометричному центрі решітки, розташованому на висоті $\mathrm{h}_{\mathrm{A}}=0,5\left(\mathrm{~h}_{\mathrm{B}}+\mathrm{h}_{\mathrm{H}}\right)$, визначається добутком ДС елемента решітки (4) на комплексний множник системи

$$
f_{N}^{\prime}(\theta)=\sum_{n=-1}^{1} a_{n} \exp \left[j\left(\phi_{n}+0,5 n k d \sin \theta\right)\right] .
$$

Отже нормована комплексна ДС антени буде

$$
\begin{gathered}
F_{A}^{\prime}(\theta)=F_{A}(\theta) e^{j \Phi_{A}(\theta)}= \\
=f_{e}(\theta) f_{N}^{\prime}(\theta) / f_{e}\left(\theta_{A}\right) f_{N}\left(\theta_{A}\right) .
\end{gathered}
$$

Амплітудно-фазовий розподіл $a_{n} \exp \left(j \phi_{n}\right)$ залежить від характеристик дільника потужності між ярусами антени. В РЛС до нижнього $(\mathrm{n}=-1)$ ярусу підводиться $60 \%$ потужності, до верхнього $(\mathrm{n}=1)-$ $40 \%$ і він збуджується сигналом з випередженням по фазі на $0,5 \pi$.

При відстані між ярусами $d=1,29 \lambda$ максимуми множника системи порядку $\mathrm{m}$, напрямки яких визначаються за формулою

$$
\sin \theta_{m N}=(\xi / k d)+m \lambda / d,
$$


при $\xi=-0,5 \pi$ формуються під кутами $\theta_{0 \mathrm{~N}}=-11,2$, $\theta-{ }_{1 \mathrm{~N}}=-75,7, \theta_{1 \mathrm{~N}}=35,6^{\circ}$.

Графік нормованого множника системи показаний на рис. 2 (штрих).

\section{$\mathrm{F}_{\mathrm{A}}(\theta)$}

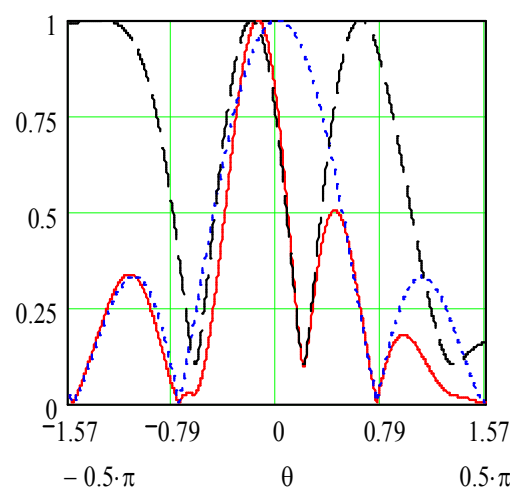

Рис. 2. Спрямовані характеристики антени

У множника системи дифракційні пелюстки мають різну ширину, бо відхилені на різні кути, провали не досягають нуля внаслідок несиметричного амплітудного розподілу. Отже, максимуми ДС елемента решітки та її множника не співпадають, що приводить до певного придушення пелюстків. Нормована амплітудна ДС антени (суцільна крива на рис. 2) несиметрична, максимуми головного і придушених дифракційних пелюсток по напрямкам та значенням змінилися по відношенню до множника системи, дифракційний пелюсток $m=-1$ в бік Землі придушений краще, ніж $m=+1$. Головний максимум ДС оріентований під кутом $\theta_{\mathrm{A}}=-8,3^{\circ}$.

На рис.3 наведена в межах головної пелюстки ДС фазова діаграма антени $\Phi_{\mathrm{A}}(\theta)$.

$$
\Phi_{\mathrm{A}}(\theta)
$$

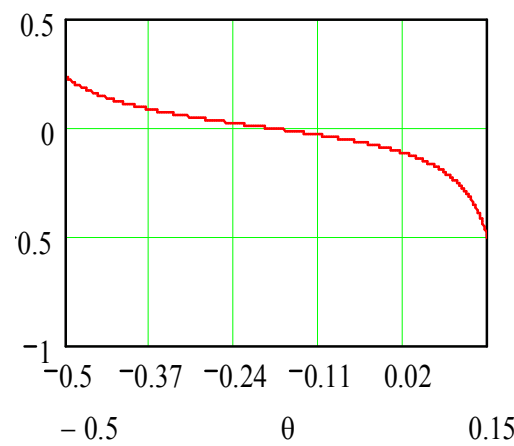

Рис. 3. Фазова характеристика антени

Вона не постійна, як це має місто для сферичного фронту хвилі. Фаза поля випромінювання по обидві сторони від напрямку головного максимуму амплітудної ДС мають різні знак і значення, що змінює різницю фаз прямої і відбитої хвилі в напрямку на ціль і впливає на результат їх інтерференції. Отже, в напрямку на ціль $(\theta>0)$ і на точку відбиття $(\theta<0)$ антена випромінює різні амплітуди і фази поля. Вирази (3), (5) визначають математичну модель зони виявлення.
Аналіз зон виявлення. На рис. 4 наведені зони виявлення РЛС з горизонтально поляризованою антеною в координатах висота $\mathrm{H}$ - дальність $\mathrm{R}$, які нормовані до максимальної дальності виявлення Д у вільному просторі, для двох висот підйому траверси антени на позиції з сухим грунтом $\left(\varepsilon=4, \sigma=10^{-3}\right)-$ суцільні криві, та морською водою $(\varepsilon=80, \sigma=4)-$ пунктир.

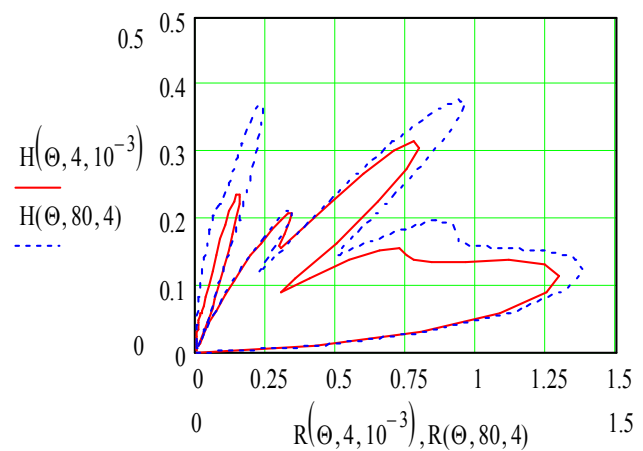

a)

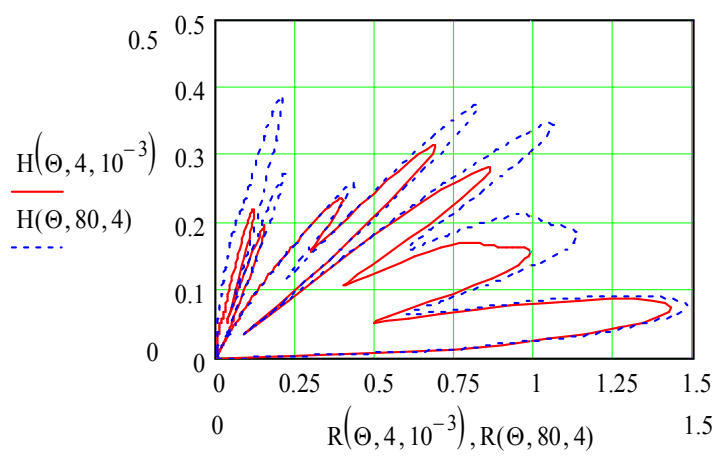

б)

Рис. 4. Нормовані зони виявлення РЛС метрового діапазону: $\mathrm{a}-\mathrm{h}_{\mathrm{A}}=2,7 \lambda ; \sigma-\mathrm{h}_{\mathrm{A}}=4,8 \lambda$

Зони виявлення доцільно аналізувати до кутів $35-40^{\circ}$, що знаходяться в межах головної пелюстки ДС директорної антени. Наведені графіки мають багатопелюсткову структуру. Кількість пелюстків, напрямки та значення екстремальних випромінювань залежать в першу чергу від висоти антени. Зі збільшенням $\mathrm{h}_{\mathrm{A}}$ умови безпровальної проводки цілей погіршуються, однак підвищуються можливості виявлення маловисотних цілей. Так, для $\mathrm{h}_{\mathrm{A}}=2,7 \lambda$ нормована стеля безпровальної проводки в межах зони виявлення для сухого грунту складає $\mathrm{H}_{\mathrm{cr}}=0,09$, нормована максимальна дальність виявлення $\mathrm{R}=1,29$, для $\mathrm{h}_{\mathrm{A}}=4,8 \lambda-\mathrm{H}_{\mathrm{cr}}=0,04, \mathrm{R}=1,43$. Збільшення дальності виявлення на малих висотах виникає внаслідок притискання нижнього пелюстка ДС до Землі (з 5 до $3^{\circ}$ ). При цьому збільшується коефіцієнт відбиття, а також сумарна амплітуда поля в напрямках $\pm 3^{\circ}$ на ціль і точку відбиття в порівнянні 3 напрямками $\pm 5^{\circ}$ (рис. 2). Більш привабливими для виявлення цілей $є$ позиції РЛС біля моря, яке в метровому діапазоні хвиль наближається до провідника. Покращання основних показників зони виявлення пов'язане зі збільшенням модуля коефіцієнта відбиття, який при горизонтальній поляризації мало 
відрізняється від одиниці. Приріст дальності виявлення стає більш примітним зі збільшенням кута $\theta$, де більш значним $є$ приріст (в порівнянні з сухим грунтом-діелектриком) коефіцієнта відбиття. Наведені результати по основним параметрам добре узгоджені з параметрами реальних зон виявлення, наведеними в [5].

У процесі бойової роботи виникає необхідність змінювати деякі параметри зони виявлення. Для цього передбачена можливість механічно нахиляти антену уверх до $+15^{\circ}$, або униз (до Землі) на $-5^{\circ}$. Нахил полотна антени на кут $\theta_{\mathrm{e}}$ повертає ДС антени без зміни iї форми так, що в напрямку на ціль і на точку відбиття її значення змінюються до величин

$$
F_{A}^{\prime}\left(\theta-\theta_{e}\right), F_{A}^{\prime}\left(-\theta-\theta_{e}\right) \text {. }
$$

На рис. 5 показані значення амплітудних ДС антени на ціль і точку відбиття для $\theta_{\mathrm{e}}=0$ (відповідно суцільна і штрих криві), $-5^{\circ}$ (суцільна крива і пунктир), $+5^{\circ}$ (суцільна крива і штрих- пунктир), а на рис. 6 - зони виявлення РЛС для $\theta_{\mathrm{e}}=0$ (суцільна крива), $-5^{\circ}$ (штрих $),+5^{\circ}$ (пунктир) для сухого грунту при висоті антени $\mathrm{h}_{\mathrm{A}}=2,7 \lambda$.

$$
\mathrm{F}_{\mathrm{A}}(\theta)
$$

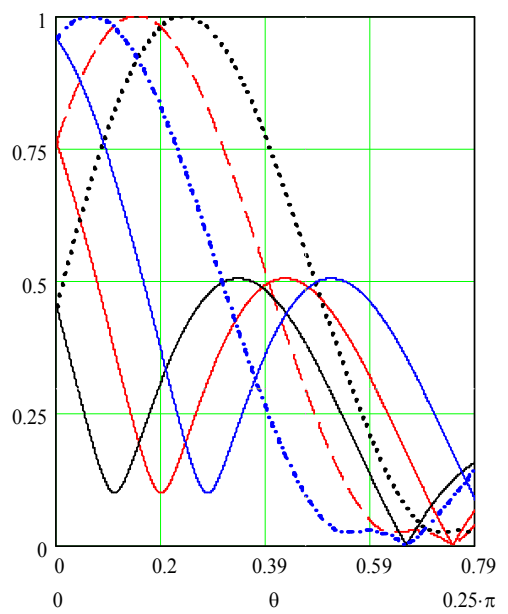

Рис. 5. Значення ДС на ціль і точку відбиття

Поворот антени уверх на $5^{\circ}$ збільшує верхню межу зони виявлення по куту місця до $42^{\circ}$, зменшує радіус вирви до значення висоти цілі, покращує умови виявлення цілей під малими кутами місця i верхній межі зони, але при цьому зменшується стеля безпровальної проводки цілі, погіршуються умови виявлення цілі під кутами місця $8 \ldots 14^{\circ}$. Збільшення дальності виявлення маловисотних цілей виникає внаслідок того, що при наближенні максимуму ДС до горизонту, збільшуються амплітуди поля випромінювання в напрямках на ціль и точку відбиття, що видно 3 рис. 5 (штрих-пунктирна сумісно 3 суцільною криві).
$\mathrm{H}(\theta)$

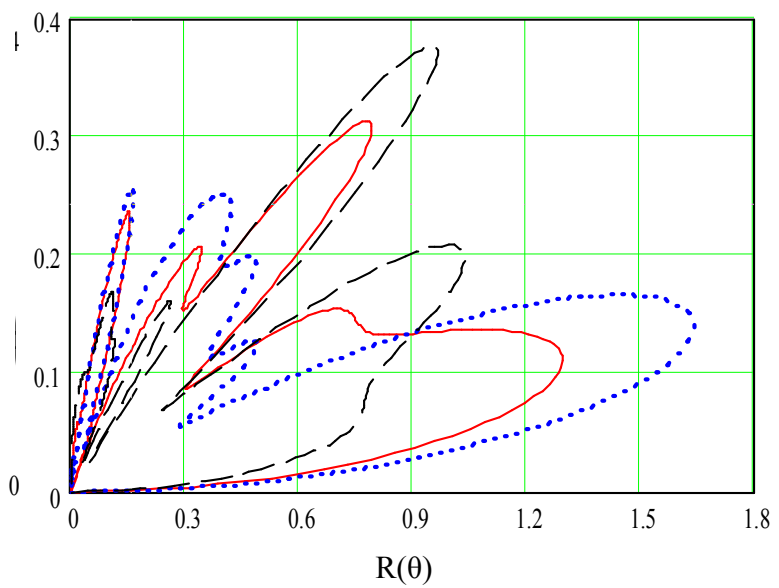

Рис. 6. Зони виявлення при різних кутах нахилу антени

При нахилі антени униз в напрямку на ціль під малими кутами випромінюється незначна амплітуда поля, тому умови виялення цілей поліпшуються лише під кутами $8 \ldots 14^{\circ}$ та $19 \ldots 25^{\circ}$, де амплітуда поля на точку відбиття стає досить значною.

\section{Висновки}

Розглянута математична модель зон виявлення РЛС метрового діапазону, розташованих на гладкій поверхні Землі. Антена внаслідок певних особливостей побудови випромінює хвилі с несферичним фронтом відносно початку вибраної системи координат.

Тому запропонована модель, яка, на відміну від відомої, містить інформацію за фазову характеристику антени, що впливає на результат інтерференції прямих і відбитих хвиль.

Проведені розрахунки зон виявлення ілюструють вплив на їх параметри електричних властивостей Замлі, висот підйому антени та її нахилу відносно горизонту. Надані фізичні пояснення отриманим результатам. Наведені дані відповідають відомим для окремих випадків результатам. Математична модель просто реалізується за допомогою доступного комп'ютерного математичного пакету Mathcad [10]. Використання комп'ютерної моделі на базі отриманої аналітичної моделі дозволяє, зокрема, при розгортанні РЛС на нових позиціях або при зміні електричних параметрів Землі оперативно оцінювати зони виявлення та можливості їх управління для покращання умов локації цілі під певними кутами місця.

Узагальнення методики визначення зон виявлення на випадки випромінювання антеною несферичного фронту хвилі надає можливість уточнити результати розрахунку приземних зон виявлення [11] та коефіцієнта використання горизонту [12].

\section{СПИСОК ЛІТЕРАТУРИ}

1. Основы радиолокации: справочник по радиолокации / Под ред. М. Сколника. Пер. с англ. под общей ред. К.Н. Трофимова. Том1, гл.2: Расчет дальности действия радиолокационной станции/ Л.Блэйк - М. : Сов. радио,1976.- 456 с.

2. Распространение радиоволн: монография / Черный Ф.Б. - М.: Сов.радио,1972. - 464 с.

3. Barton D. Radar systems analysis and modeling/ David K. Barton// - Boston, MA Artech. House 2004. - 545 p. 
4. Мобільна радіолокаційна станція П-18. Будова, принцип дії систем та пристроїв: навчальний посібник/ Тхоржевський В.І., Тхоржевський І.В., Вишневський В.В., Гахович С.В. та ін. - К. : ТОВ «Чайка-Всесвіт», 2006. - 162 с.

5. Озброєння підрозділів і частин радіотехнічних військ ППО ПС. Оглядова РЛС П-18Р: навчальний посібник для військ. Частина 1: навчальний матеріал / В.І. Ткаченко, Д.А. Гриб, М.Д. Рисаков, С.А. Макаров, В.І. Василишин, В.Г. Карєв, О.П. Кулик. - Харківський університет Повітряних Сил. - Харків, 2008 - 389с.

6. Корнієнко Л.Г. До визначення поля системи випромінювачів, піднятих над земною поверхнею / Л.Г. Корнієнко //Системи обробки інформації. - 2018.- №4.- С.37-41

7. Вычислительные методы в электродинамике: монография / под ред. Р. Митры, пер. с англ. Под ред.Э.Л. Бурштейна.М.: Мир, 1977.- 486c.

8. Антенны: учебное пособие/ Шифрин Я.С. - Х.: ВИРТА, 1976. -408 с.

9. Антенны и устройства СВЧ: учеб. для радиотехнич. спец. вузов / Сазонов Д.М. - М.: Высш.шк., 1988. -432 с.

10. . Самоучитель Mathcad 11: монография / Кирьянов Д.В. - СПб.: БХВ-Петербург, 2003.- 560с.

11. Приземные зоны видимости РЛС с учетом влияния сферичности Земли и радиорефракции / Н.А. Арманд, В.А. Андрианов, Б.В. Ракитин и др. - М.: ИРЭ АН СССР, 1977. - 80 с.

12. Климченко В.Й. Особливості розрахунку коефіцієнта використання радіогоризонту в оглядових РЛС метрового діапазону хвиль / В.Й. Климченко, Г.Г. Камалтинов, І.Л. Єфімов // Озброєння та військова техніка. Науково-технічний журнал. - ЦНДІ ОВТ - 2016. - № 4 (12). - С. 27-31.

Рецензент: д-р техн. наук, проф. Л. Ф. Купченко, Харківський національний університет імені Івана Кожедуба, Харків Received 18.07.2018

Accepted for publication 19.09.2018

\title{
Зоны обнаружения РЛС метрового диапазона с учетом особенностей построения и использования антенной системы Л. Г. Корниенко, В. Д. Карлов, А. Н. Артеменко
}

Предметом исследования является методика расчета зон обнаружения РЛС метрового диапазона, на формирование которой существенное влияние оказывает Земля. Целью работы является разработка и анализ математической модели зоны обнаружения, которая обобщает известную модель на случай, когда антенна РЛС не имеет фазового центра или он не совпадает с началом выбранной системы координат для расчета диаграммы направленности антенны. Модель базируется на методе отражательной трактовки и учитывает особенности построения антенны. Излучающие элементы антенны в виде волновых каналов расположены на двух этажах, что позволяет подбором высот этажей и их возбуждения сигналами с определенными амплитудами и начальными фазами уменьшить глубину провалов в диаграмме направленности в определенных угловых секторах. В таких антеннах обычно отсутствует фазовый центр, поэтому в математической модели зоны обнаружения учтены не только амплитудные, но и фазовые характеристики антенны. Это позволило учесть различия фаз полей в направлениях на цель и точку отражения и уточнить результат интерференции прямых и отраженных волн. Проведены расчеты зон обнаружения, иллюстрирующие влияние на их параметры электрических свойств земли, высот подъема антенны и ее наклона относительно горизонта. Математическая модель реализована с помощью доступного и простого компьютерного математического пакета Mathcad. Компьютерная модель позволяет при изменениях конструкции антенны или электрических параметров Земли оперативно оценивать зоны обнаружения и возможности их управления для улучшения условий обнаружения целей под определенными углами места.

Ключевы е слов а: зона обнаружения, метод отражательной трактовки, прямая и отраженная волны, электрические параметры земной поверхности, коэффициент отражения, высота подъема приемно-передающей антенны, амплитудная и фазовая диаграммы, интерференционный множитель, максимальная дальность обнаружения.

\section{Zones detection metric radars \\ with the account of the peculiarities of construction and use of the antenna system}

\author{
L. Kornienko, V. Karlov, A. Artemenko
}

The subject of the study is the methodology for calculating the radar detection zones of the meter range, the formation of which is significantly influenced by the Earth. The aim of the work is the development and analysis of the mathematical model of the detection zone, which generalizes the known model to the case when the radar antenna does not have a phase center or it does not coincide with the beginning of the chosen coordinate system for calculating the antenna pattern. The model is based on the method of reflective interpretation and takes into account the features of antenna construction. The radiating elements of the antenna in the form of wave channels are located on two floors, which makes it possible to select the heights of floors and their excitation with signals with certain amplitudes and initial phases to reduce the depth of the dip in the radiation pattern in certain angular sectors. In such antennas there is usually no phase center, therefore, in the mathematical model of the detection zone, not only the amplitude, but also the phase characteristics of the antenna are taken into account. This made it possible to take into account the differences in the phases of the fields in the directions to the target and the reflection point and to clarify the result of the interference of the direct and reflected waves. The calculations of the detection zones illustrating the effect on their parameters of the electric properties of the ground, elevations of the antenna and its inclination with respect to the horizon are carried out. The mathematical model is realized with the help of an accessible and simple computer mathematical package Mathcad. The computer model allows, with changes in the design of the antenna or electrical parameters of the Earth, to promptly estimate the detection zones and their control capabilities to improve the conditions for detecting targets at certain elevation angles.

Keywords: detection zone, reflection method, direct and reflected waves, electrical parameters of the earth's surface, reflection coefficient, height of the receiving and transmitting antenna, amplitude and phase diagrams, interference multiplier, maximum detection range. 